\title{
We Have Moved On: Current Concepts and Positions in Generative SLA
}

\author{
$1,2, *$ ROUMYANA SLABAKOVA, \\ ${ }^{3}$ TANIA L. LEAL and ${ }^{2}$ JUDITH LISKIN-GASPARRO \\ ${ }^{1}$ University of Southampton, ${ }^{2}$ University of Iowa and ${ }^{3}$ Indiana University \\ *E-mail: R.Slabakova@soton.ac.uk
}

\begin{abstract}
In this Forum piece, we address several common misunderstandings of the generative L2A framework that are current in the wider L2A literature. Many of these misunderstandings stem from proposals that, although tested and eventually discarded, are still cited as though they were still accepted and in active use. We hope that by addressing four of the most persistent myths, we can persuade the wider L2A field to let them go and move on. By highlighting what generative researchers have in common with the proponents of other frameworks, we want to pave the way for increased collaboration between frameworks.
\end{abstract}

In our reading and conversations with graduate students and colleagues, we have encountered persistent myths in the wider second language acquisition (SLA) community's perceptions about the positions taken by generative L2 researchers. 'Generative' grammar refers to a finite set of universal rules (Universal Grammar) that generate all (and only) sentences that are acceptable in a given language. These (unconscious) rules form the basis of L2 acquisition (L2A); upon encountering target language input, native rules are reset and new rules are acquired. Although the input to learners is different, the null hypothesis of L2A is that it is fundamentally similar to child L1A, being human language acquisition.

We offer the present update to address several common misunderstandings of the generative L2A framework. Many of these misunderstandings stem from proposals that, although tested and eventually discarded, are still cited as though they were still accepted and in active use. We hope that by addressing four of the most persistent myths, we can persuade the wider SLA field to let them go and move on. By highlighting what generative researchers have in common with the proponents of other frameworks, we want to pave the way for increased collaboration between frameworks. 


\section{INSTANTANEOUS PARAMETER SETTING?}

The most persistent myth about the generative L2 framework is that its proponents hold that parameters are reset in an instant and bring a host of constructions into the grammar. Although instantaneous parameter resetting was once accepted, it is now of historical significance only. However, the notion of 'instantaneous acquisition' (Jordan 2004: 152) is still considered to be part and parcel of parameter resetting.

In his original formulation of language acquisition, Chomsky (1986) proposed that, apart from universal properties (principles), language-specific properties could be described by parameters: a small number of options provided by Universal Grammar for controlled variation. At the time, the light switch was an apt metaphor. Among the first parameters studied in child language acquisition was the Null Subject Parameter (NSP) (Hyams 1986); proponents at that time argued that English-speaking children start with the null-subject value of the parameter and later reset it to the correct value. The switch metaphor contributed to the perception of instantaneous, successful acquisition; switches are either on or off, with no in-between state.

Conceptually, it was attractive to think of parameters as single-value changes that brought a host of superficially unrelated constructions into the grammar. For the NSP, the proposed cluster of constructions included null subjects, null expletives, postverbal subjects, that-trace effects, and rich subject-verb agreement (Rizzi 1982). Once a learner-child or adult-acquired null subjects, the whole cluster of associated constructions would become part of his/her grammar.

Nevertheless, early L2 generative studies on the NSP (e.g. White 1985) showed that not all of the purportedly related constructions were acquired simultaneously. Research on other parametric clusters (White 1990) led to similarly mixed results. Finally, the Feature Reassembly Hypothesis (Lardiere 2009) dealt a fatal blow to the notions of instantaneous acquisition and parametric clustering.

Lardiere's model, considered the most robust one to date, views L2A as a two-step process of mapping and (re)assembly of formal feature matrices. The first step is based on perceived similarities between the functional meanings of L2 and L1 lexical items (reminiscent of Contrastive Analysis). Similarities lead to an initial feature mapping of Ll items onto target items. For example, Spanish-speaking learners of English typically map the Spanish imperfect onto the English past progressive because they partially overlap in meaning. The next step involves feature reassembly: features can be added or deleted, gradually adjusted based on input-based evidence for meaning and usage. For the English progressive tense, noticing its unavailability with stative verbs and the absence of habitual interpretation should result in alterations to the feature set. Feature reassembly may occur slowly or not at all if the relevant evidence in the input is rare or ambiguous. Hence, no instantaneous resetting of parameters is expected. 


\section{GENERATIVE SLA IGNORES CONTEXT?}

Van Lier (2011: 386) counts generative SLA among the linguistic theories that ignore context. Indeed, various SLA approaches have different definitions of context. While generative linguists do not normally engage with context in the larger social sense, they do focus on the discourse context of the utterance under consideration. Such context includes the text or speech preceding the utterance that allows the nominal(s) in it to be activated in the mind of the speaker and hearer (topic), or introduced as new information (focus). In the past decade, a profusion of studies (e.g. Belletti et al. 2007; Ivanov 2012) has explored the effect of the immediate context on acceptability judgements by L2 speakers. Semantic notions such as genericity, definiteness, and specificity, which depend on speaker/hearer assumptions about the discourse context, have also been extensively investigated (e.g. Ionin et al. 2013).

\section{GENERATIVE SLA DISREGARDS INPUT?}

The importance of input is a point on which generative and usage-based accounts converge. Primary linguistic data have always been recognized within the generative framework as crucial for setting parameter values. Recent research provides a welcome push towards a formal treatment of synchronic variation in the input. Chomsky (2005) re-emphasized the importance of input, identifying three factors that determine the properties of the human language faculty: (i) the genetic endowment; (ii) linguistic experience (comprehensible input); and (iii) principles of data analysis and efficient computation (not specific to the language faculty). Currently, generative researchers heed O'Grady et al. (2009) warning that, in considering the role of input frequency in language acquisition, it is of vital importance how frequently learners encounter mappings between a form and its meaning.

Yang's (2002) Variational Learning Model, which unifies parameter setting with general learning mechanisms based on frequency of parametric evidence, is gaining theoretical and empirical support. This insight is not new, but it is now becoming mainstream. Yang proposes that although parameters constrain the hypothesis space of the child, parameters that are supported with abundant, unambiguous evidence in the input will be learned earlier than parameters for which the supporting evidence is scarce.

A growing body of research in generative SLA has studied the acquisition of grammatical features in situations of inconsistent or infrequent parametric evidence. To study the effect of variable input in child acquisition, Miller and Schmitt (2010) exploited dialectal differences in Spanish plural morphology. Mexican Spanish realizes plural overtly as [s], whereas in Chilean Spanish (subject to sociolinguistic variation) plural morphology is reduced to aspiration [h] or to nothing. Because it is pronounced only about half the time, Chilean plural morphology is unreliable as linguistic evidence. Results showed that Chilean working-class 5 -year-olds were only $32 \%$ accurate in 
understanding the meaning of plural, whereas age-matched Mexican workingclass children were $77 \%$ accurate. The authors argue that increased variability and ambiguity in the input increases the time needed to converge on the adult grammar.

In another study in generative SLA that examines acquisition in light of input frequency, Montrul (2009) argues that reduced input is a primary cause of the potential incomplete Ll acquisition in heritage speakers. She offers an interesting twist on the Critical Period Hypothesis: although heritage speakers should achieve native-like competence in their first (heritage) language because they are childhood acquirers, often they do not. It seems that an early start may not be crucial in language acquisition; in contrast, high-quality linguistic input may be essential.

In sum, linguistic input has emerged as perhaps the key factor in addressing the fundamental question of differences between native and L2 acquisition.

\section{THE NATIVE SPEAKER HOAX: GENERATIVE LINGUISTS THINK ALL NATIVE SPEAKERS SPEAK THE LANGUAGE PERFECTLY?}

Many non-generative L2 researchers have asked why generative linguists tolerate so much variation in native judgements when we put such stock in NS competence. As Chipere (1997) phrased it, 'the idea of a perfectly competent but resource-limited language user is the basis of many models of sentence comprehension'. This was indeed the predominant understanding in the 1960s and 1970s, but it is not any longer.

Generative acquisitionists nowadays speak of proficient and non-proficient native speakers (NSs) and acknowledge that exposure is the key to correct comprehension and usage. In an investigation of the qualitative and quantitative effects of register, Meisel et al. (2011) examined several French interrogative constructions that differ in frequency within specific registers (colloquial vs formal speech). French children are virtually never exposed to subject-verb inversion (Quand arrive le train? *When arrives the train?) until they learn standard French in school. Consequently, subject-verb inversion may be learned as an L2 construction and thus may be inherently unstable, even in native grammars. Meisel et al. (2011) found that although French adult NSs consistently accepted colloquial French interrogative constructions, standard French interrogatives exhibited wider cross-individual and intra-individual variability. The authors concluded that the grammar of these speakers 'comprises islands of non-native knowledge' (Meisel et al. 2011: 380).

This conclusion raises crucial questions about what comprises native and non-native language knowledge and how they are different. If limited exposure to a particular construction results in Ll variability, then non-native 
grammars, also characterized by variability, may not be qualitatively different from native ones with regard to these constructions.

\section{CONCLUSIONS}

We hope we have shown that generative SLA inquiry has expanded and evolved. As its original concept of parameters was challenged by L2 data, generative theorists have proposed new acquisition models, capitalizing on linguistic variation and the robustness of support for parameters in the linguistic input. Although it maintains a focus on the genesis of the internal grammatical system of the learner, generative SLA has moved beyond its original focus on the emergence of morpho-syntax. Many interesting developments currently come from research on the linguistic interfaces: syntax-discourse, syntaxphonology, syntax-semantics. Research in generative SLA is characterized by attention to: (i) processing and other cognitive constructs (e.g. inhibitory control); (ii) linguistic input, including construction frequency; and (iii) formmeaning mismatches between the L1 and L2, operationalized as re-assembly of grammatical and semantic features. Generative SLA research should no longer be considered on the fringe of SLA research.

\section{REFERENCES}

Belletti, A., E. Bennati, and A. Sorace. 2007. 'Theoretical and developmental issues in the syntax of subjects: evidence from near-native Italian,' Natural Language and Linguistic Theory 25: 657-89.

Bordón, T. and J. Liskin-Gasparro. 2014. 'Assessment and evaluation in Spanish' in M. Lacorte (ed.): The Routledge Handbook of Hispanic Applied Linguistics. Routledge, pp. 258-74.

Chipere, N. 1997. 'Real language users,' available at http://cogprints.org/712/1/real.html.

Chomsky, N. 1986. Knowledge of Language. Praeger.

Chomsky, N. 2005. 'Three factors in language design,' Linguistic Inquiry 36/1: 1-22.

Hyams, N. 1986. Language Acquisition and the Theory of Parameters. Reidel.

Ionin, T., S. Montrul, and M. Crivos. 2013. 'A bidirectional study on the acquisition of plural noun phrase interpretation in English and Spanish,' Applied Psycholinguistics 34: 483-518.

Ivanov, I. 2012. 'L2 acquisition of Bulgarian clitic doubling: A test case for the Interface Hypothesis,' Second Language Research 28: 345-368.
Jordan, G. 2004. Theory Construction in Second Language Acquisition. John Benjamins.

Lardiere, D. 2009. 'Some thoughts on a contrastive analysis of features in second language acquisition,' Second Language Research 25/2: $173-227$.

Liskin-Gasparro, J. and R. Vasseur. In press. 'Designing an embedded outcomes assessment for Spanish majors: literary interpretation and analysis' in J. Norris and N. Mills (eds): Innovation and Accountability in Foreign Language Program Evaluation. Cengage.

Meisel, J. M., M. Elsig, and M. Bonnesen. 2011. Delayed grammatical acquisition in first language development: subject-verb inversion and subject clitics in French interrogatives,' Linguistic Approaches to Bilingualism 1/4: 347-90.

Miller, K. and C. Schmitt. 2010. 'Effects of variable input in the acquisition of plural in two dialects of Spanish,' Lingua 120: $1178-93$.

Montrul, S. 2009. 'Re-examining the fundamental difference hypothesis: what can early bilinguals tell us?' Studies in Second Language Acquisition 31/2: 225-57 
O'Grady, W., M. Lee, and H. Y. Kwak. 2009. 'Emergentism and second language acquisition,' in W. Ritchie and T. Bhatia (eds): The New Handbook of Second Language Acquisition. Emerald Press, pp. 69-88.

Rizzi, L. 1982. Issues in Italian Syntax. Foris.

Slabakova, R. 2001. Telicity in the Second Language. John Benjamins Publishing Company.

Slabakova, R. 2008. Meaning in the Second Language. Mouton de Gruyter.

van Lier, L. 2011. 'Language learning: an ecological-semiotic approach,' in E. Hinkel (ed.):
Handbook of Research in Second Language Teaching and Learning, vol. 2. Taylor and Francis, pp. 383-94.

White, L. 1985. "The "pro-drop" parameter in second language acquisition,' Language Learning 35/1: 47-61.

White, L. 1990. 'The verb-movement parameter in second language acquisition,' Language Acquisition, 1/4: 337-60.

Yang, C. 2002. Knowledge and Learning in Natural Language. University Press. 


\section{NOTES ON CONTRIBUTORS}

Roumyana Slabakova is a Professor and Chair of Applied Linguistics at the University of Southampton, UK, and Professor of Linguistics at the University of Iowa, where she taught previously. Her research interest is in the second language acquisition of meaning, more specifically phrasal-semantic, discourse, pragmatic meanings. Her monographs include Telicity in the Second Language (Benjamins 2001) and Meaning in the Second Language (Mouton de Gruyter 2008). She co-edits the journal Linguistic Approaches to Bilingualism (Benjamins). She is working on a textbook of generative second language acquisition to be published by Oxford University Press. Address for correspondence: Roumyana Slabakova, Department of Modern Languages, Building 65, University of Southampton, Southampton SO17 1BF, UK. <R.Slabakova@soton.ac.uk>

Tania L. Leal is a postdoctoral scholar in the Department of Spanish and Portuguese at Indiana University. She holds a Ph.D. in Second Language Acquisition with an emphasis in Linguistics from the University of Iowa. Her research, which has focused on the acquisition of syntax and syntax-pragmatics, can be found in journals such as the International Journal of Bilingualism, Lingua, and Language Acquisition. Her most recent work focuses on individual differences and sentence processing in a second language. $<$ tlealmen@gmail.com>

Judith Liskin-Gasparro is an Associate Professor in the Department of Spanish and Portuguese at the University of Iowa and the Co-Director of Foreign Language Acquisition Research and Education (FLARE) and its interdisciplinary doctoral programme in Second Language Acquisition. Her research centres on the acquisition and assessment of speaking skills in classroom and study abroad contexts and the assessment of student learning outcomes. Her recent work includes a chapter on assessment and evaluation in Spanish (The Routledge Handbook of Hispanic Applied Linguistics, 2014) and a chapter on the assessment of the learning outcomes in literary interpretation and analysis of undergraduate Spanish majors (Cengage 2014). She is also an author of Mosaicos, Unidos, and Identidades, elementary and intermediate Spanish textbooks (Pearson). <judith-liskin-gasparro@uiowa.edu> 